Check for updates

Cite this: RSC Adv., 2017, 7, 32413

\title{
Facile construction of gemini-like surfactants at the interface and their effects on the interfacial tension of a water/model oil system†
}

\author{
Hongtao Zhou, ${ }^{* a}$ Hongyan Wu, ${ }^{a}$ Yuping Yang, ${ }^{b}$ Xu Leng, ${ }^{a}$ Yipu Liang, ${ }^{\text {a }}$ Peng Lian, ${ }^{a}$ \\ Yilei Song, ${ }^{a}$ Zewen $\mathrm{Yi}{ }^{a}$ Jingping Liu ${ }^{\mathrm{a}}$ and Han Jia (D) *a
}

\begin{abstract}
The application of supramolecular chemistry may be a promising and convenient approach to construct desired surfactants via noncovalent interactions in various fields, including chemical enhanced oil recovery (EOR). Gemini-like surfactants were fabricated by combining sodium dodecyl benzene sulfonate (SDBS) and butane-1,4-bis(methylimidazolium bromide) (BBMB) at the interface and evaluated for their ability to reduce the interfacial tension (IFT) between water and a model oil (toluene and $n$ decane, $v / v=1: 1)$. The SDBS/BBMB molar ratio at the interface, but not in the bulk phase, was the crucial factor in the construction of gemini-like surfactants and the reduced level of IFT. Based on the synergistic effect between electrostatic attraction and other intermolecular or intramolecular interactions ( $\pi-\pi$ stacking and hydrophobic interaction), the formation mechanism of gemini-like surfactants was proposed. The effects of temperature and salinity on the IFT were systematically investigated. Moreover, the (SDBS) 2 /BBMB gemini-like surfactant system showed the desired ability to reduce the IFT of water/ crude oil and a great improvement in crude oil recovery.
\end{abstract}

Received 7th April 2017

Accepted 13th June 2017

DOI: $10.1039 / c 7 r a 03973 e$

rsc.li/rsc-advances

were efficient in EOR in the above reports, their complicated

\section{Introduction}

Surfactant flooding can effectively mobilize residual oil from mature reservoirs as a significant method towards enhanced oil recovery (EOR). ${ }^{1}$ Traditional surfactants hardly satisfy the practical requirements of unconventional reservoirs with harsh environments; therefore, many groups have researched and developed novel high-performance surfactants. ${ }^{2-5}$ Compared with single chain surfactants, gemini surfactants have exhibited specific physical and chemical properties. For example, the surface/interface activity of gemini surfactants is orders of magnitude higher than that of single-chain surfactants. ${ }^{6-14}$ The oil/water interfacial tension (IFT) reduction is the main mechanism of surfactant flooding. Thus, gemini surfactants have great potential for EOR application. ${ }^{15-25}$ Chen et al. found that cationic gemini surfactants could reduce the IFT between model oil or crude oil and water to ultralow values. ${ }^{15-17}$ Recently, Nguele and coworkers proposed a recovery method for heavy crude oils by injecting fully emulsified oil (formulated by cationic gemini surfactants). ${ }^{25}$ Although gemini surfactants

${ }^{a}$ College of Petroleum Engineering, China University of Petroleum (East China), Qingdao, 266580, China. E-mail: zhouht@upc.edu.cn; jiahan@upc.edu.cn; Tel: +86-532-86981901; +86-532-86981663

${ }^{b}$ CNPC Drilling Research Institute, No. 1 Building, No. 5 Hospital, Huanghe Street, Changping, Beijing, 102206, China

$\dagger$ Electronic supplementary information (ESI) available. See DOI: $10.1039 / \mathrm{c} 7 \mathrm{ra03973e}$ synthetic method and correspondingly high price may greatly restrict their applications. Therefore, this study attempts to find facile methods to fabricate gemini-like surfactants without tedious covalent synthesis and complex purification at the interface.

Creating gemini-like surfactants via the noncovalent interactions of appropriate monomers may be a convenient approach since supramolecular chemistry was first proposed and widely accepted. Noncovalent interactions, mainly including electrostatic attraction, hydrogen bonding, hostguest recognition, and metal-ligand coordination, have been employed to construct supramolecular amphiphiles. ${ }^{\mathbf{2 6 - 3 0}}$ Noncovalent interactions have been applied to the fabrication of gemini-like surfactants in recent years. The synergistic effects between the electrostatic interaction and other intermolecular or intramolecular interactions may be the most effective and facile approach to construct gemini-like surfactants. ${ }^{31-41}$ Feng et al. designed two $\mathrm{pH}$-switchable gemini-like surfactants using a bola-type dicarboxylic acid or salt and a single-chain surfactant with opposite charge. ${ }^{31-33}$ Wang's group systematically investigated the effects of single-chain structures in surfactants on the properties of obtained gemini-like surfactants. ${ }^{34,35}$ The above reports focused on the versatile phase behaviours of gemini-like surfactants in solution; however, the authors believe that the construction of gemini-like surfactants may produce remarkable effects on the interfacial system activity, which has scarcely been reported. 
Recently, Sun et al. fabricated a gemini-like surfactant utilizing the spacers butane-1,4-bis(methylimidazolium bromide) (BBMB) and the single-chain surfactant sodium dodecyl benzene sulfonate (SDBS) in solution. ${ }^{40}$ The addition of spacer molecules could induce vesicle formation in solution. Herein, the gemini-like surfactants were fabricated by combining SDBS and BBMB at the interface, and the ability of the gemini-like surfactants to reduce the IFT of water/model oil was evaluated. It was found that the optimal SDBS/BBMB molar ratio to construct the gemini-like surfactant at the interface was different from that in the bulk phase. The effects of temperature and salinity on the IFT were systematically investigated. In addition, the gemini-like surfactant system was further evaluated in a water/crude oil system.

\section{Experimental}

\section{Chemicals}

Sodium dodecyl benzene sulfonate (SDBS, 95\%) was purchased from Shanghai Chemical Reagent Co. Ltd. and recrystallized in methanol prior to use. Sodium dodecyl sulfate (SDS, 98\%), sodium chloride, toluene, and $n$-decane were purchased from Aladdin Chemical Reagent Company. 1-Methylimidazole (98\%), 1,4-dibromo-butane (98\%), and 1-bromododecane (98\%) were the products of J\&K Chemical Company. All of the chemicals were of analytical grade and used without further purification.

The crude oil was obtained from Jidong oilfield. The main composition and properties of crude oil are shown in Table S1. $\dagger$ The composition of the used formation brine is also given in Table S2. $\dagger$

Butane-1,4-bis(methylimidazolium bromide) (BBMB, Fig. S1 $\dagger$ ) and 1-dodecyl-3-methylimidazolium bromide (M12) were synthesized following techniques presented in previous literature. ${ }^{\mathbf{4 0 , 4 2}}$ The purities were confirmed by the ${ }^{1} \mathrm{H}$ NMR spectrum with a Bruker Avance 300 spectrometer.

\section{Measurement of interfacial tension}

The interfacial tension between the model oil (toluene and $n$ decane, $\mathrm{v} / \mathrm{v}=1: 1$ ) and water was directly measured via the spinning drop method on a TX-500C spinning drop interfacial tension apparatus (American CNG Company) as previously described. ${ }^{\mathbf{4 3 4 4}}$ The aqueous solution was primarily filled in the glass tube. Then, droplet model oil was injected into the centre of the water phase. Finally, the interfacial tension was measured at a fixed rotating velocity $(5000 \mathrm{rpm})$ at a given temperature.

\section{Core flooding tests}

The artificial core used for the flooding test was $5.0 \mathrm{~cm}$ in diameter, with a length of $60 \mathrm{~cm}$. The core wettability was water wet. The core porosity is approximately $40 \%$, and the absolute permeability is $\sim 500 \mathrm{mD}$. The core flooding test was performed at $30^{\circ} \mathrm{C}$, which was briefly described as follows. Firstly, the core was saturated using brine, followed by the injection of crude oil until no more production of brine (brine cut $<1 \%$ ). Then, the core was flooded with the brine until the negligible oil production (oil cut $<1 \%$ ). Next, a 0.5 PV slug of the chemical formula brine solution was injected. Finally, an extended water slug was injected until the oil cut became nearly 0 percent. The injection rate was set at $2.0 \mathrm{~mL} \mathrm{~min}^{-1}$.

\section{Results and discussion}

Model oil consisting of toluene and $n$-decane (v/v = $1: 1)$ was used to replace crude oil to avoid the influence of impurities (gelatin, asphaltene and other uncertain matters) in the mixtures.

\section{Effects of (SDBS) $)_{2} /$ BBMB gemini-like surfactants on the interfacial tension (IFT) of water/model oil}

As shown in Fig. 1, the additional BBMB molecules can produce drastic effects on the IFT between the SDBS aqueous solutions and model oil. The IFT value changes appear to be closely related to the SDBS/BBMB molar ratios $(R)$. When the number of SDBS molecules is much more than or roughly equal to that of BBMB molecules $(R=10: 1,5: 1,2: 1,1: 1$, and $1: 2)$, the IFT values sharply decreased with the increased BBMB concentration. The excess BBMB molecules $(R=1: 5$ and $1: 10)$ are detrimental to the further reduction of IFT values, and the change tendency of IFT curves is completely opposite. The additional BBMB molecules can also exert the remarkable influence on the dynamic IFT (Fig. 2). The time to the balance IFT value is shorten with the more BBMB molecules. It's worth noting that the dynamic IFT is increased to the balance value at the $R$ of $1: 5$ and $1: 10$.

As is well known, the electrostatic repulsion of the head group can disturb the ordered arrangement of the surfactant molecules at the interface and decelerate the adsorption velocity of subsequent surfactant molecules. ${ }^{45}$ It is found that the additional BBMB molecule is a typical bola-type organic salt without apparent interfacial activity (Table S3†). The BBMB molecules can interact with SDBS molecules in at least two respects. On the one hand, an electrostatic attraction exists

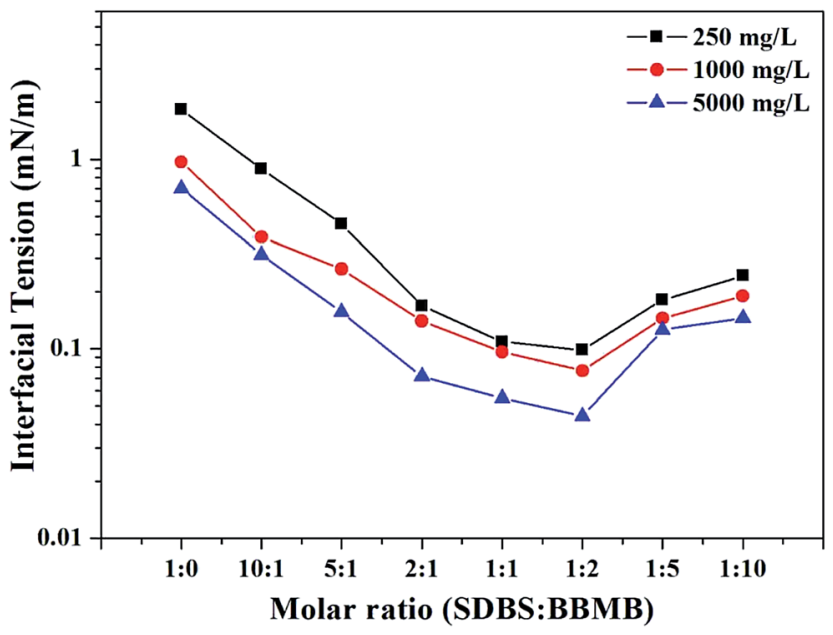

Fig. 1 Effects of additional BBMB molecules on the IFT between SDBS aqueous solutions ( $250 \mathrm{mg} \mathrm{L}^{-1}, 1000 \mathrm{mg} \mathrm{L}^{-1}$, and $5000 \mathrm{mg} \mathrm{L}^{-1}$ ) and model oil at $30^{\circ} \mathrm{C}$. 


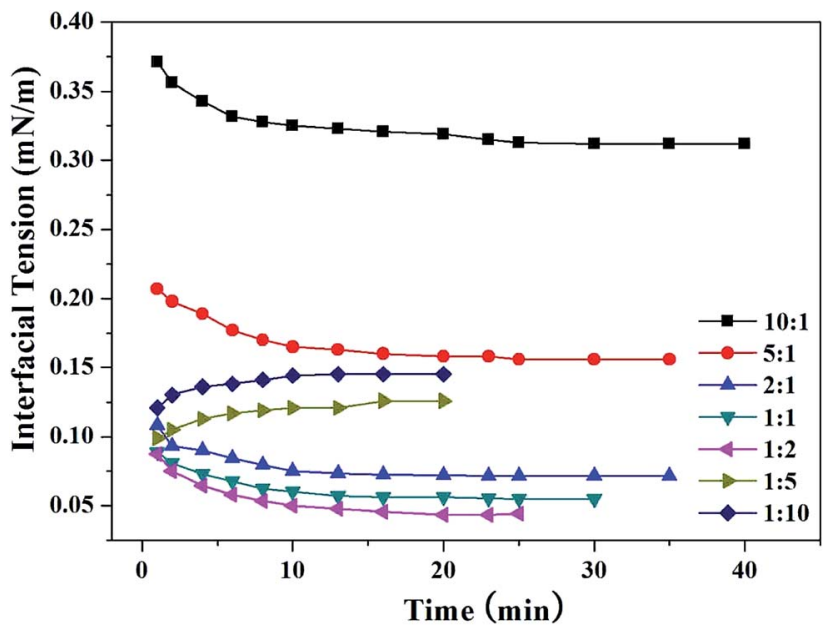

Fig. 2 Effects of additional BBMB molecules on the dynamic IFT between model oil and SDBS aqueous solutions $\left(5000 \mathrm{mg} \mathrm{L}^{-1}\right)$ with different SDBS/BBMB molar ratios at $30^{\circ} \mathrm{C}$.

between the imidazole BBMB ring with positive charges and the anionic SDBS head group. On the other hand, the $\pi-\pi$ stacking between the imidazole BBMB ring and the SDBS benzene ring cannot be neglected. One BBMB molecules can "bridge" two SDBS molecules, leading to the constructions of the (SDBS) ${ }_{2} /$ BBMB gemini-like surfactants at the interface. The hydrophobic interactions among the SDBS chains in one or adjacent geminilike surfactants may promote the arrangement of SDBS molecules. Besides, the BBMB molecule may "connect" the adjacent gemini-like surfactants by the $\pi-\pi$ stacking, which is beneficial to the compact arrangement of the gemini-like surfactants at the interface. Thus, the synergistic effect between electrostatic attraction and other intermolecular or intramolecular interactions ( $\pi-\pi$ stacking and hydrophobic interaction) plays the significant roles in the formations of gemini-like surfactants. Due to the closer arrangement and the higher effective concentration of SDBS molecules at the interface, the IFT was largely decreased.

In the previous literature, gemini-like surfactants were successfully constructed in a mixed SDBS/BBMB solution at the $R$ of $2: 1 .^{40}$ Further, the molar ratio of $2: 1$ is considered to be the optimal ratio to fabricate gemini-like surfactants using single-chain ionic surfactants and bola-type organic matters (base, acid, and salt) with opposite charges. ${ }^{6}$ In the present study, the lowest IFT value $\left(0.0443 \mathrm{mN} \mathrm{m}^{-1}\right)$ is achieved at the $R$ of $1: 2$ but not at $2: 1$. The "effective" concentration may be the key factor to explain the above difference. The interfacial activity of SDBS is much higher than that of BBMB (Fig. 1 and Table S3 $†$ ). The SDBS molecules at the interface can attract the BBMB molecules in the bulk phase to prompt the construction of the gemini-like surfactants. Then the more additional BBMB molecules can shorten the time of the dynamic IFT to the balance value (Fig. 2). Thus, the bulk phase concentration may not reflect the effective interface concentration. Although $R$ is $1: 2$ in solution, the effective molar ratio must be higher at the interface. It is reasonable to obtain the lowest IFT value at the $R$ of $1: 2$. If $R$ is $1: 5$ or $1: 10$, a large number of BBMB molecules could diffuse into the interface and destroy the initial geminilike surfactant construction due to the excessively high BBMB concentration in the bulk phase, leading to the increase of the dynamic IFT (Fig. 2). The IFT should be increased with the increased concentration of BBMB with weak interfacial activity at the interface.

\section{Verification of the assembly mechanism of the (SDBS $)_{2} / \mathrm{BBMB}$ gemini-like surfactant at the interface}

In general, the addition of salts (e.g., $\mathrm{NaCl})$ can largely reduce the IFT by neutralizing the head group charges of the ionic surfactants. ${ }^{45}$ The effects of BBMB, as a typical organic salt, should be deeply explored to determine whether the construction of a gemini-like surfactant or the normal "salt effect" occurs. Thus, $\mathrm{NaCl}$ replaced BBMB in the control experiment (Table 1). It is evident that the level of IFT reduction is moderate with the additional $\mathrm{NaCl}$. The IFT value for the SDBS $/ \mathrm{NaCl}$ system is almost one order of magnitude larger than that for the SDBS/BBMB system at high concentration. Furthermore, the number of $\mathrm{NaCl}$ molecules is much more than that of BBMB molecules at the same mass concentration. Thereby, a special interaction must occur in the SDBS/BBMB system. The following two similar/control surfactants were used to further verify the possible interaction: sodium dodecyl sulfate (SDS), an anionic surfactant without a conjugated $\pi$ bond, and 1-dodecyl3-methylimidazolium bromide (M12), a cationic surfactant with a conjugated $\pi$ bond at the head group. As shown in Fig. 3, the mixed SDBS/BBMB system, the SDS/BBMB system, and the M12/BBMB system can decrease the IFT from $0.701 \mathrm{mN} \mathrm{m}^{-1}$, $0.967 \mathrm{mN} \mathrm{m}^{-1}$, and $4.319 \mathrm{mN} \mathrm{m}^{-1}$ to $0.0443 \mathrm{mN} \mathrm{m}^{-1}, 0.484 \mathrm{mN}$ $\mathrm{m}^{-1}$, and $2.491 \mathrm{mN} \mathrm{m}^{-1}$, respectively (IFT values in Table $\mathrm{S} 4, \dagger$

Table 1 Effects of $\mathrm{NaCl}$ and BBMB on the IFT between SDBS aqueous solutions $\left(5000 \mathrm{mg} \mathrm{L}^{-1}\right)$ and model oil at $30{ }^{\circ} \mathrm{C}$

\begin{tabular}{lllll}
\hline & \multicolumn{2}{l}{ SDBS/NaCl system } & & \multicolumn{2}{l}{ SDBS/BBMB system } \\
\cline { 2 - 3 } Salt concentration $\left(\mathrm{mg} \mathrm{L}^{-1}\right)$ & SDBS/NaCl molar ratio & IFT $\left(\mathrm{mN} \mathrm{m}^{-1}\right)$ & & SDBS/BBMB molar ratio \\
\hline 546 & $10: 6.5$ & 0.67654 & $10: 1$ & 0.312 \\
1090 & $5: 6.5$ & 0.57186 & $5: 1$ & 0.156 \\
2730 & $2: 6.5$ & 0.45779 & $2: 1$ & 0.0714 \\
5460 & $1: 6.5$ & 0.32827 & $1: 1$ & 0.0550 \\
10900 & $1: 13$ & 0.17318 & $1: 2$ & 0.0443
\end{tabular}




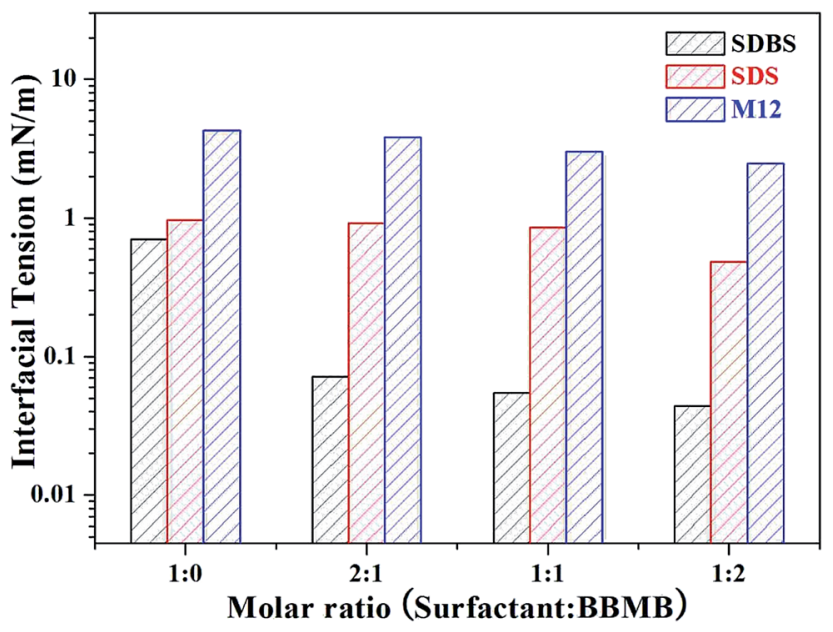

Fig. 3 Effects of additional BBMB molecules on the IFT between different surfactant aqueous solutions $\left(5000 \mathrm{mg} \mathrm{L}^{-1}\right)$ and model oil at $30{ }^{\circ} \mathrm{C}$.

dynamic IFT in Fig. S2 $\dagger$ ). The IFT reduction degrees for the three systems are obviously different and are attributed to the interactions between surfactant molecules and BBMB molecules. For the SDS/BBMB system, the electrostatic attraction is dominant, whereas the $\pi-\pi$ stacking is the crucial interaction in the M12/BBMB system. The gemini-like surfactants in the SDS/BBMB or M12/BBMB systems, constructed by the sole interaction, may be loose at the interface, resulting in the slight IFT reduction. Besides, the electrostatic repulsion between M12 and $\mathrm{BBMB}$ head groups can disturb the construct process of the gemini-like surfactants. The dynamic IFT in the M12/BBMB system firstly decrease and then slightly increase to the balance value, which is distinctly different to that in SDBS/ BBMB or SDS/BBMB system (Fig. S2 $\dagger$ ). Based on the above results, the synergistic effect between electrostatic attraction and other intermolecular or intramolecular interactions $(\pi-\pi$

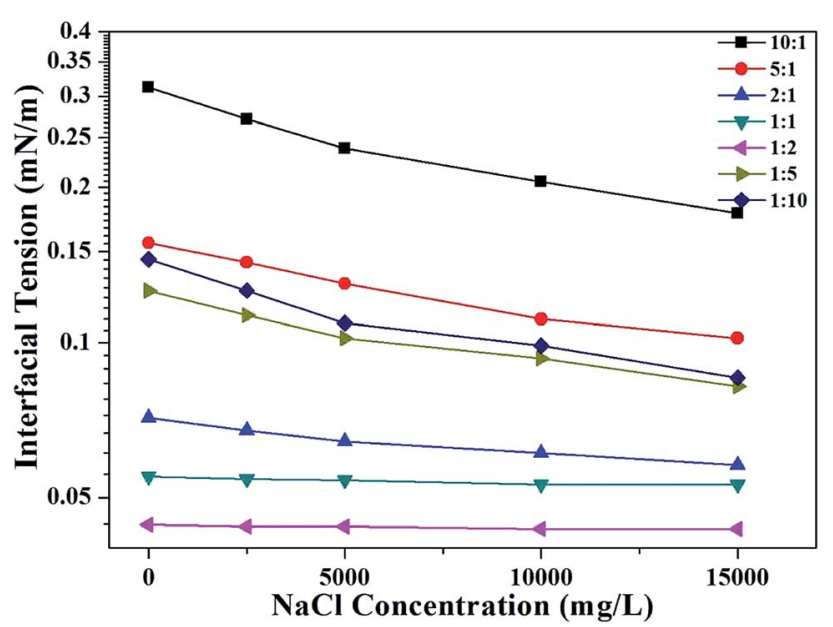

Fig. 4 Effects of $\mathrm{NaCl}$ concentrations on the IFT between mixed SDBS (5000 $\mathrm{mg} \mathrm{L}^{-1}$ ) and BBMB aqueous solutions with different molar ratios and model oil at $30^{\circ} \mathrm{C}$. stacking and hydrophobic interaction) is further verified to be the predominant factor in the constructions of the (SDBS $)_{2} /$ BBMB gemini-like surfactant at the interface.

\section{Effects of $\mathrm{NaCl}$ concentration and temperature on the IFT between model oil and mixed SDBS/BBMB aqueous solutions}

It is well known that temperature and salinity are the two most significant factors that affect the IFT of oil/water. In the proposed system, the effects of additional $\mathrm{NaCl}$ are discrepant for the systems with different $R$ values (Fig. 4). The model of a "gemini-like surfactant" is employed to explain the difference. If $R$ is too large or too small $(10: 1,5: 1,1: 5$, and $1: 10)$, the reduced level of the IFT is relatively great. When $R$ is too large (10: 1 and $5: 1$ ), there are abundant "free" SDBS molecules at the interface due to a lack of "bridging BBMB molecules". For the mixed SDBS/BBMB system at the $R$ of $1: 5$ and $1: 10$, an excess of additional BBMB molecules may destroy the geminilike surfactant structures to generate "free" molecules at the interface. Then, the inorganic salt can neutralize the "free" surfactant molecule charges to further reduce the IFT. If the number of SDBS molecules is roughly equal to that of BBMB molecules $(R=2: 1,1: 1$, and $1: 2)$, the gemini-like surfactant molecules are dominant at the interface. A strong interaction between SDBS and BBMB molecules exists, so the salt effects may be neglected, leading to the nearly flat IFT change curve.

As shown in Fig. 5, there is an evidently increasing tendency for all seven IFT curves with increased temperature. It is notable that the increased level of the IFT is relatively low at the $R$ of $1: 5$ and $1: 10$. The surfactant type explains the temperature effects on the IFT. Based on the phase inversion temperature (PIT) theory, the effects of temperature on the IFT are discussed for nonionic surfactant systems. ${ }^{\mathbf{4 4}}$ In the present study, the hydrophilicities of ionic surfactant SDBS and organic salt BBMB systems are enhanced with increased temperature. ${ }^{46}$ A great number of SDBS and BBMB molecules will desorb from the interface and enter the bulk phase, resulting in the IFT increase.

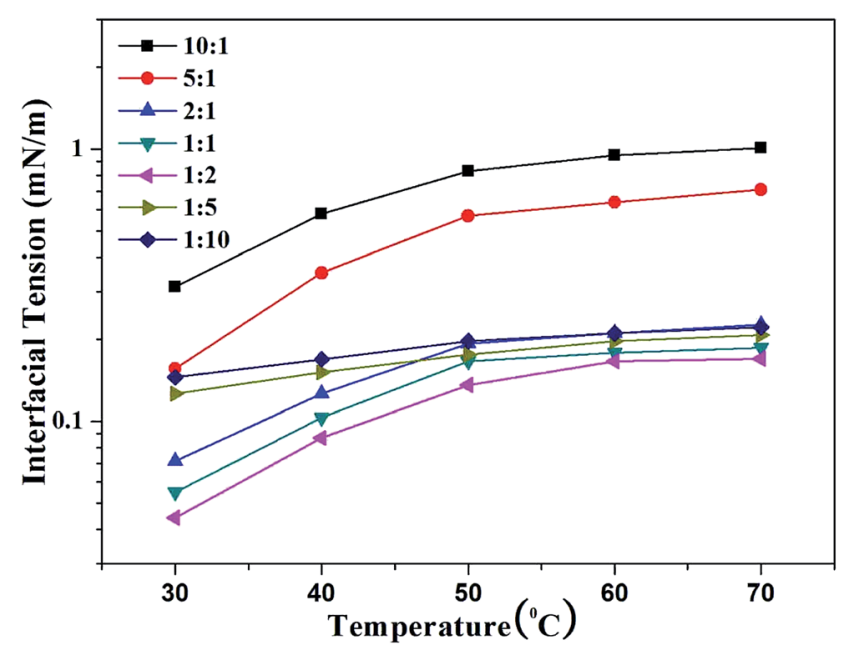

Fig. 5 Effects of temperatures on the IFT between mixed SDBS (5000 $\mathrm{mg} \mathrm{L}^{-1}$ ) and BBMB aqueous solutions with different molar ratios and model oil. 


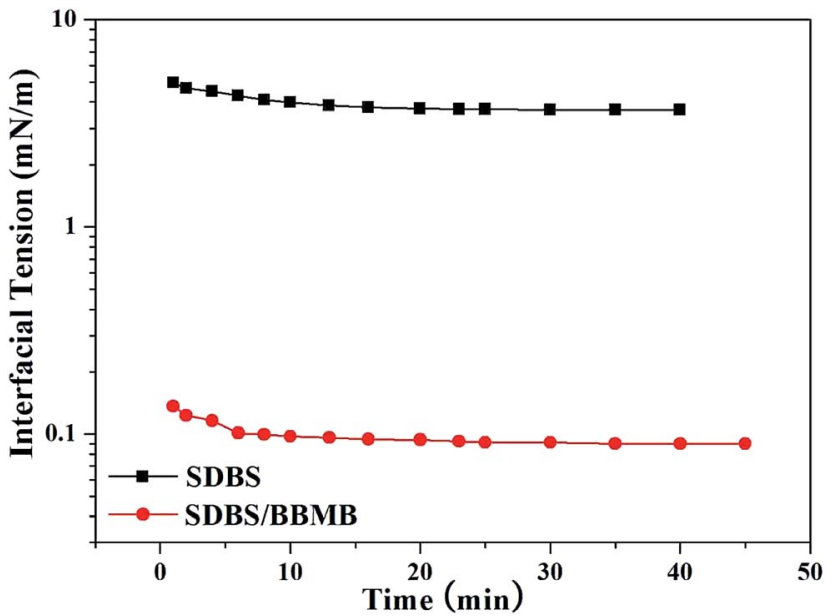

Fig. 6 Dynamic IFT between the SDBS $\left(5000 \mathrm{mg} \mathrm{L}^{-1}\right)$ or the mixed $\operatorname{SDBS} / \mathrm{BBMB}\left(R=1: 2\right.$, [SDBS] $\left.=5000 \mathrm{mg} \mathrm{L}^{-1}\right)$ brine solution and crude oil at $30^{\circ} \mathrm{C}$.

When $R$ is $1: 5$ or $1: 10$, the excess BBMB molecules can retard the SDBS desorption via electrostatic attraction, lowering the IFT increased degree.

\section{The applications of the (SDBS) $)_{2} /$ BBMB gemini-like surfactant in core flooding tests}

The above results suggest that the mixed SDBS/BBMB system at $R$ of $1: 2$ has the optimum interfacial activities for a water/ model oil system. Then the selected system is further evaluated in a water/crude oil system. Due to the uncertain impurities in crude oil, the IFT value obviously increases for the water/crude oil system in brine solution, which is much lower than that for SDBS system (Fig. 6). Then flooding tests were performed in cores to exam the potential of the (SDBS $)_{2} / \mathrm{BBMB}$ gemini-like surfactant for EOR in waterflooded oil reservoirs. The main parameters of cores, chemical formula compositions, and flooding effects are summarized in Table 2 and Fig. 7. It is noteworthy that the (SDBS) $)_{2}$ BBMB gemini-like surfactant has shown the satisfactory displacement performances $(\sim 10 \%$ of IOIP (initial oil in place)), which is much higher than that for individual SDBS system $(\sim 4 \%$ of IOIP). The results of core tests demonstrate that the constructions of the $(\mathrm{SDBS})_{2} / \mathrm{BBMB}$ gemini-like surfactant can further enhance the incremental crude oil recovery.

\section{Conclusions}

In conclusion, SDBS and BBMB were employed to successfully fabricate gemini-like surfactants at the interface. It was found that the optimal SDBS/BBMB molar ratio to construct the gemini-like surfactant at the interface was completely different from that in the bulk phase. At the optimal SDBS/BBMB molar ratio of $2: 1$, the constructed gemini-like surfactants could effectively reduce the IFT of water/model oil to the much low value $\left(0.0443 \mathrm{mN} \mathrm{m}^{-1}\right)$. Compared with the effects of additional $\mathrm{NaCl}$, SDS, and M12 in the control experiments, the synergistic effect between the electrostatic attraction and other intermolecular or intramolecular interactions $(\pi-\pi$ stacking and hydrophobic interaction) was found to play a significant role in

Table 2 Summary of core flooding tests

\begin{tabular}{llllllll}
\hline $\begin{array}{l}\text { Core } \\
\text { no. }\end{array}$ & $\begin{array}{l}\text { Porosity } \\
(\%)\end{array}$ & $\begin{array}{l}\text { Permeability } \\
(\mathrm{mD})\end{array}$ & $\begin{array}{l}\text { Initial oil } \\
\text { saturation }(\%)\end{array}$ & $\begin{array}{l}\text { Waterflood } \\
\text { recovery }(\%)\end{array}$ & $\begin{array}{l}\text { Chemical } \\
\text { formula }\end{array}$ & $\begin{array}{l}\text { Tertiary recovery } \\
(\% \text { IOIP) }\end{array}$ & $\begin{array}{l}\text { Final recovery } \\
(\% \text { IOIP) }\end{array}$ \\
\hline a & 40.13 & 543 & 87.23 & 36.6 & SDBS $\left(5000 \mathrm{mg} \mathrm{L}^{-1}\right)$ & 4.0 \\
b & 38.20 & 516 & 88.70 & 32.0 & $\begin{array}{l}\text { SDBS/BBMB }(R=1: 2) \\
\text { [SDBS] }=5000 \mathrm{mg} \mathrm{L}^{-1}\end{array}$ & 9.8 & 40.6 \\
\end{tabular}
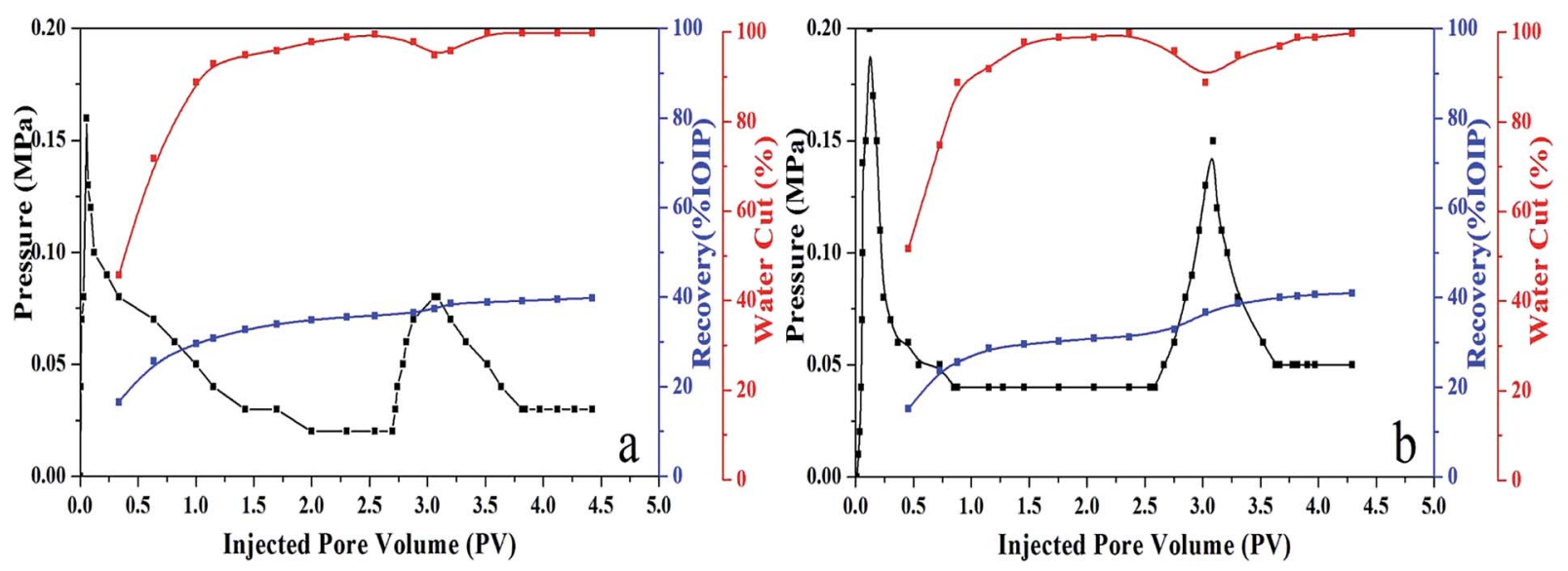

Fig. 7 Results of core flooding tests in Table 2. 
the formation of gemini-like surfactants. Further, the geminilike surfactant model was used to perfectly explain the effects of temperature and salinity on the IFT. Moreover, the (SDBS) $)_{2} /$ BBMB gemini-like surfactant showed the satisfactory ability to reduce the IFT of water/crude oil, leading to the prominent improvement $(10 \%$ of IOIP) of tertiary oil recoveries in core flooding tests. The present study proposes a simple and promising approach to construct desired surfactants with new features in the field of chemical EOR.

\section{Acknowledgements}

The authors are grateful for funding from the National Natural Science Foundation of China (No. 21403301), the Basic Fundamental Research Funds of Qingdao (16-5-1-41-jch), the Fundamental Research Funds for the Central Universities (16CX02058A), the foundation of Key Laboratory of Colloid and Interface Chemistry (Shandong University), Ministry of Education (201402) and National Training Program of Innovation and Entrepreneurship for Undergraduates (No. 201710425011).

\section{References}

1 H. J. Butt, K. Graf and M. Kappl, Physics and Chemistry of Interfaces, Wiley-VCH, Weinheim, 2nd edn, 2008.

2 T. Tichelkamp, E. Teigen, M. Nourani and G. Øye, Chem. Eng. Sci., 2015, 132, 244-249.

3 S. Kumar and A. Mandal, Appl. Surf. Sci., 2016, 372, 42-51.

4 H. H. Khanamiri, M. Nourani, T. Tichelkamp, J. A. Stensen, G. Øye and O. Torsæter, Energy Fuels, 2016, 30, 984-991.

5 J. Lu, P. J. Liyanage, S. Solairaj, S. Adkins, G. P. Arachchilage, D. H. Kim, C. Britton, U. Weerasooriya and G. A. Pope, J. Pet. Sci. Eng., 2014, 120, 94-101.

6 L. Y. Zhu, Y. Q. Tang and Y. L. Wang, J. Surfactants Deterg., 2016, 19, 237-247.

7 M. J. Rosen and D. J. Tracy, J. Surfactants Deterg., 1998, 1, 547-554.

8 L. R. Dix and R. Gilblas, J. Colloid Interface Sci., 2006, 296, 762-765.

9 M. Akram, S. Yousuf, T. Sarwar and Kabir-ud-Din, Colloids Surf., A, 2014, 441, 281-290.

10 L. Lai, P. Mei, X. M. Wu, L. Chen and Y. Liu, Colloids Surf., A, 2016, 509, 341-350.

11 N. Fatma, M. Panda and Kabir-ud-Din, J. Mol. Liq., 2016, 219, 959-966.

12 C. Wang, X. L. Cao, L. L. Guo, Z. C. Xu, L. Zhang, Q. T. Gong, L. Zhang and S. Zhao, Colloids Surf., A, 2016, 509, 601-612.

13 S. M. S. Hussain, M. S. Kamal and A. S. Sultan, J. Surfactants Deterg., 2017, 20, 47-55.

14 A. A. Muslim, D. Ayyash, S. S. Gujral, G. M. Mekhail, P. P. N. Rao and S. D. Wettig, Phys. Chem. Chem. Phys., 2017, 19, 1953-1962.

15 H. Chen, L. J. Han, P. Y. Luo and Z. B. Ye, Surf. Sci., 2004, 552, L53-L57.

16 H. Chen, L. J. Han, P. Y. Luo and Z. B. Ye, J. Colloid Interface Sci., 2005, 285, 872-874.
17 Z. B. Ye, F. X. Zhang, L. J. Han, P. Y. Luo, J. J. Yang and H. Chen, Colloids Surf., A, 2008, 322, 138-141.

18 Y. J. Guo, J. X. Liu, X. M. Zhang, R. S. Feng, H. B. Li, J. Zhang, X. Lv and P. Y. Luo, Energy Fuels, 2012, 26, 2116-2123.

19 J. X. Liu, Y. J. Guo, J. Hu, J. Zhang, X. Lv, X. M. Zhang, X. S. Xue and P. Y. Luo, Energy Fuels, 2012, 26, 2858-2864.

20 B. Gao and M. M. Sharma, J. Colloid Interface Sci., 2013, 407, 375-381.

21 M. A. Ahmadi and S. R. Shadizadeh, J. Pet. Sci. Eng., 2013, 110, 66-73.

22 A. Labena, M. A. Hegazy, H. Horn and E. Muller, J. Surfactants Deterg., 2014, 17, 419-431.

23 B. F. Hou, Y. F. Wang and Y. Huang, Appl. Surf. Sci., 2015, 330, 56-64.

24 M. S. Kamal, J. Surfactants Deterg., 2016, 19, 223-236.

25 R. Nguele, K. Sasaki, Y. Sugai, B. Omondi, H. S. Al-Salim and

R. Ueda, Energy Fuels, 2017, 31, 255-270.

26 X. Zhang and C. Wang, Chem. Soc. Rev., 2011, 40, 94-101.

27 C. Wang, Z. Q. Wang and X. Zhang, Acc. Chem. Res., 2012, 45, 608-618.

28 S. Böttcher and S. Drusch, Adv. Colloid Interface Sci., 2017, 243, 105-113.

29 X. Q. Dou and C. L. Feng, Adv. Mater., 2017, 29, 1604062.

30 K. S. Mali, N. Pearce, S. D. Feyter and N. R. Champness, Chem. Soc. Rev., 2017, 46, 2520-2542.

31 Z. Chu and Y. Feng, Chem. Commun., 2010, 46, 9028-9030.

32 Y. Zhang, Y. Feng, Y. Wang and X. Li, Langmuir, 2013, 29, 4187-4192.

33 Y. Feng and Z. Chu, Soft Matter, 2015, 11, 4614-4620.

34 D. Yu, M. Tian, Y. Fan, G. Ji and Y. L. Wang, J. Phys. Chem. B, 2012, 116, 6425-6430.

35 Y. Tang, Z. Liu, L. Zhu, Y. Han and Y. L. Wang, Langmuir, 2015, 31, 2104-2111.

36 Y. Q. Tang, R. J. Wang and Y. L. Wang, J. Surfactants Deterg., 2015, 18, 25-31.

37 S. Noori, A. Z. Naqvi, W. H. Ansari, M. Akram and D. Kabirud, J. Surfactants Deterg., 2013, 17, 409-417.

38 C. Zhou, X. Cheng, O. Zhao, S. Liu, C. Liu, J. Wang and J. Huang, Soft Matter, 2014, 10, 8023-8030.

39 J. Zhao, D. Yang and Y. You, J. Surfactants Deterg., 2014, 17, 583-589.

40 N. Sun, L. J. Shi, F. Lu, S. T. Xie and L. Q. Zheng, Soft Matter, 2014, 10, 5463-5471.

41 Y. Li, H. Li, J. Chai, M. Chen, Q. Yang and J. Hao, Langmuir, 2015, 31, 11209-11219.

42 H. Jia, X. T. Bai and L. Q. Zheng, CrystEngComm, 2011, 13, 7252-7257.

43 H. T. Zhou, Y. G. Zhu, T. Peng, Y. L. Song, J. B. An, X. Leng, Z. W. Yi, Y. Q. Sun and H. Jia, J. Mol. Liq., 2016, 223, 516-520.

44 H. Jia, Y. L. Song, D. Jiang, L. J. Xing, X. Leng, Y. G. Zhu, J. B. An, A. D. Dong, C. Q. Jia and H. T. Zhou, Colloids Surf., A, 2017, 513, 292-296.

45 F. F. Lv, L. Q. Zheng, Y. A. Gao, G. Z. Li and Z. H. Tong, Chin. J. Chem., 2005, 23, 957-962.

46 T. Forster, W. V. Rybinski and A. Wadle, Adv. Colloid Interface Sci., 1995, 58, 119-149. 